https://helda.helsinki.fi

\title{
Saccadic eye movements estimate prolonged time awake
}

\section{Pettersson, Kati}

2019-04

Pettersson, K, Mueller , K, Tietavainen , A , Gould , K \& Haeggstrom , E 2019 , ' Saccadic eye movements estimate prolonged time awake ', Journal of Sleep Research , vol. 28 , no. 2 , 12755 . https://doi.org/10.1111/jsr.12755

http://hdl.handle.net/10138/313507

https://doi.org/10.1111/jsr.12755

unspecified

publishedVersion

Downloaded from Helda, University of Helsinki institutional repository.

This is an electronic reprint of the original article.

This reprint may differ from the original in pagination and typographic detail.

Please cite the original version. 


\title{
Saccadic eye movements estimate prolonged time awake
}

\author{
Kati Pettersson ${ }^{1}(\mathbb{D}) \mid$ Kiti Müller ${ }^{2,3}$ | Aino Tietäväinen ${ }^{4}$ | Kristian Gould ${ }^{5}$ | \\ Edward Hæggström ${ }^{4}$
}

\author{
${ }^{1}$ Finnish Institute of Occupational Health, \\ Helsinki, Finland \\ ${ }^{2}$ Nokia Bell Labs, Espoo, Finland \\ ${ }^{3}$ Department of Neurology, University of \\ Helsinki, Helsinki, Finland \\ ${ }^{4}$ Department of Physics, University of \\ Helsinki, Helsinki, Finland \\ ${ }^{5}$ Statoil ASA, Fornebu, Norway

\section{Correspondence} \\ Kati Pettersson, Finnish Institute of \\ Occupational Health, Topeliuksenkatu 41b, \\ 00250 Helsinki, Finland. \\ Email: kati.pettersson@ttl.fi \\ Funding information \\ Tekes - The Finnish Funding Agency for \\ Technology and Innovation, Grant/Award \\ Number: Seamless Patient and Health Care \\ project 1939/31/2015; Academy of Finland, \\ Grant/Award Number: 286154
}

\begin{abstract}
Prolonged time awake increases the need to sleep. Sleep pressure increases sleepiness, impairs human alertness and performance and increases the probability of human errors and accidents. Human performance and alertness during waking hours are influenced by homeostatic sleep drive and the circadian rhythm. Cognitive functions, especially attentional ones, are vulnerable to circadian rhythm and increasing sleep drive. A reliable, objective and practical metrics for estimating sleepiness could therefore be valuable. Our aim is to study whether saccades measured with electrooculography (EOG) outside the laboratory could be used to estimate the overall time awake without sleep of a person. The number of executed saccades was measured in 11 participants during an 8-min saccade task. The saccades were recorded outside the laboratory (Naval Academy, Bergen) using EOG every sixth hour until $54 \mathrm{hr}$ of time awake. Measurements were carried out on two occasions separated by 10 weeks. Five participants participated in both measurement weeks. The number of saccades decreased during sustained wakefulness. The data correlated with the three-process model of alertness; performance differed between participants but was stable within individual participants. A mathematically monotonous relation between performance in the saccade task and time awake was seen after removing the circadian rhythm component from measured eye movement data. The results imply that saccades measured with EOG can be used as a time-awake metric outside the laboratory.
\end{abstract}

KEYWORDS

electro-oculography, on-site, sleepiness metrics, time between saccades

\section{1 | INTRODUCTION}

Prolonged time awake increases the need to sleep (sleep pressure). Increasing sleep pressure eventually induces rapid and uncontrolled sleep initiation that leads to unstable cognitive performance (Fimm \& Blankenheim, 2016; Lim \& Dinges, 2008), which is comparable to alcohol intoxication (Dawson \& Reid, 1997; Williamson \& Feyer, 2000). Sleepiness causes $10 \%-20 \%$ of traffic accidents (e.g. Åkerstedt, 2000; Gonçalves et al., 2015) and hence is a major identifiable and preventable cause of accidents (Åkerstedt, 2000). Even though the severity of sleepiness-related accidents and hazards has been recognised, there is no reliable on-site sleepiness tester comparable to a breathalyser for blood alcohol concentration. Many objective sleepiness monitoring and detecting systems have been developed (e.g. Ahlstrom et al., 2013; Johns, Chapman, Crowley, \& Tucker, 2008); however, they measure changes in alertness and cannot estimate how long a person has been awake (time awake). A reliable, objective and practical metrics for measuring sleepiness on-site is needed (Bioulac et al., 2017; Durmer \& Dinges, 2005).

Human performance and alertness during the waking hours are influenced by both homeostatic sleep drive (S-process) and the circadian rhythm (C-process). The S-process increases as wakefulness continues, whereas the $\mathrm{C}$-process has a sinusoidal form driven by 
endogenous oscillation featuring a period of about $24 \mathrm{hr}$ (e.g. Achermann \& Borbély, 2003; Åkerstedt \& Folkard, 1997). Cognitive functions, especially attentional ones, are susceptible to both the sleep pressure and circadian rhythm (e.g. Goel, 2017; Van Dongen \& Dinges, 2005). Moreover, sleep deprivation affects individuals differently and cognitive deficits differ between individuals but are rather stable within individuals (e.g. Van Dongen, Baynard, Maislin, \& Dinges, 2004).

The Psychomotor Vigilance Task (PVT) has often been used to study the alerting subsystem of attention. PVT is a reaction-time test that is sensitive to sleep deprivation (e.g. Lim \& Dinges, 2008). The numbers of lapses, omissions and commissions, and reaction times in PVT increase in acute and cumulative sleep deprivation (e.g. Basner, Mcguire, Goel, Rao, \& Dinges, 2015; Doran, Dongen, \& Dinges, 2001; Lim \& Dinges, 2008; Van Dongen \& Dinges, 2003). This unstable performance is potentially a result of attention lapses and microsleeps caused by wake-state instability (e.g. Doran et al., 2001; Durmer \& Dinges, 2005).

Oculomotor and attentional functions share neuroanatomical networks in the brain (Casarotti, Lisi, Umiltà, \& Zorzi, 2012; Corbetta \& Shulman, 2002). Therefore, saccadic eye movement has been used to study attentional functions (e.g. Corbetta \& Shulman, 2002; Lee, Manousakis, Fielding, \& Anderson, 2015). Additionally, oculomotor parameters have been shown to be sensitive to sleep deprivation in laboratory studies (e.g. Bocca \& Denise, 2006; De Gennaro, Ferrara, Curcio, \& Bertini, 2001; De Gennaro, Ferrara, Urbani, \& Bertini, 2000; Fimm \& Blankenheim, 2016; Porcu, Ferrara, Urbani, Bellatreccia, \& Casagrande, 1998; Wachowicz et al., 2015).

The saccade task is a neurobehavioural task, which permits simultaneous assessment of attention and sleepiness. Performance parameters (e.g. saccade latency) measure visuospatial attention and oculomotor parameters (e.g. saccade peak velocity, accuracy) measure the decrement of arousal (compared with a baseline) (Bocca \& Denise, 2006).

Increasing homeostatic sleep drive has been reported to increase the number of errors in responses (omissions and commissions) in a saccade task, suggesting failures in sustaining attention (Wachowicz et al., 2015). Porcu et al. (1998) found, in a stepwise saccade task, a significant linear trend between prosaccade error rate (fraction of rejected saccades) and time awake after one night of sleep deprivation. Our earlier results showed a similar result: the number of correctly executed saccades decreased during acute sleep deprivation both in overlap and gap paradigms (Hirvonen et al., 2010). However the two latter studies did not provide detailed information about the rejected saccades.

Saccade latencies increase in prolonged time awake (e.g. De Gennaro et al., 2001; De Gennaro et al., 2000; Ferrara, Gennaro, \& Bertini, 2000; Fransson et al., 2008), especially in the overlap paradigm (Ahlstrom et al., 2013; Fimm \& Blankenheim, 2016). Bocca and Denise (2006) found that the gap effect (difference between overlap and gap latencies) increased after one night of sleep deprivation, suggesting disengagement of attention was impaired.
Saccade peak velocity is a measure of alertness. Peak velocity of visually guided prosaccades has been reported to decrease after prolonged time awake (e.g. Ahlstrom et al., 2013; De Gennaro et al., 2000; Ferrara et al., 2000; Fimm \& Blankenheim, 2016; Fransson et al., 2008; Grace, Stanford, Gentgall, \& Rolan, 2010; Zils, Sprenger, Heide, Born, \& Gais, 2005), and is affected by the underlying circadian rhythm (e.g. De Gennaro et al., 2001; Hirvonen et al., 2010) and by sleep inertia (Ferrara et al., 2000). Saccade accuracy is usually described by the gain ratio between executed saccade amplitude and target amplitude. If the saccade hits the target, the gain is 1 , whereas hypometric saccades undershoot (gain $<1$ ) and hypermetric saccades overshoot (gain $>1$ ) the target. In the literature, saccade accuracy results are not consistent. Saccades have been reported to be unaffected by prolonged time awake ( $40 \mathrm{hr}$ ) (De Gennaro et al., 2000). On the other hand, some studies have described that saccades become hypometric after one night of sleep deprivation (Bocca \& Denise, 2006; Zils et al., 2005) and hypermetric during nocturnal hours (Porcu et al., 1998).

Earlier studies carried out in the laboratory environment have shown that performance and oculomotor parameters measured during a saccade task are influenced by overall time awake of a subject. However, precise saccade task analyses require event by event analyses to classify each saccade response to a stimulus. Thus, triggering between the eye movement recording device and stimulus software is needed. The aim of our study was to examine whether overall time awake can be estimated reliably outside the laboratory from saccadic eye movements. Our proposed method does not require triggering between the eye movement recording device and stimulus software. To test the feasibility of this approach we used data collected in Hirvonen et al.'s (2010) study. The saccades were recorded outside the laboratory (Naval Academy, Bergen) during an 8-min saccade task using electro-oculography (EOG) every sixth hour until $54 \mathrm{hr}$ of time awake.

\section{MATERIALS AND METHODS}

\section{1 | Participants}

Eleven male navigators from the Royal Norwegian Navy (RNoN) volunteered for this study (mean $=26.6$; SD, 2.2; range, 23-30 years). The measurements were made on two occasions separated by 10 weeks. Eight participants participated in the first measurement week. Three of these navigators were deployed to an international mission during the 10-week washout period and were unable to participate in the second study week. Three additional RNoN navigators were recruited for the second week to allow the study to be completed. Hence, only five participants participated in both measurement weeks.

The participants were subject to extensive medical screening before acceptance into the naval academy (including psychiatric issues). Before the study the Hospital Anxiety and Depression Scale (HADS) (Zigmond \& Snaith, 1983) was used to determine levels of experienced anxiety and depression. Sleep disorders and abnormal 
FIGURE 1 Study protocol. The study protocol consists of 10 similar test cycles (top chart). Each cycle started with navigation in a simulator. After simulation and questionnaires there was an 80-min period of vision tests, one of which was the saccade task. The vision tests were performed in cycles with alternating and different kinds of vision tests (bottom chart). Saccade task data measured with electro-oculography (EOG) are presented in this study

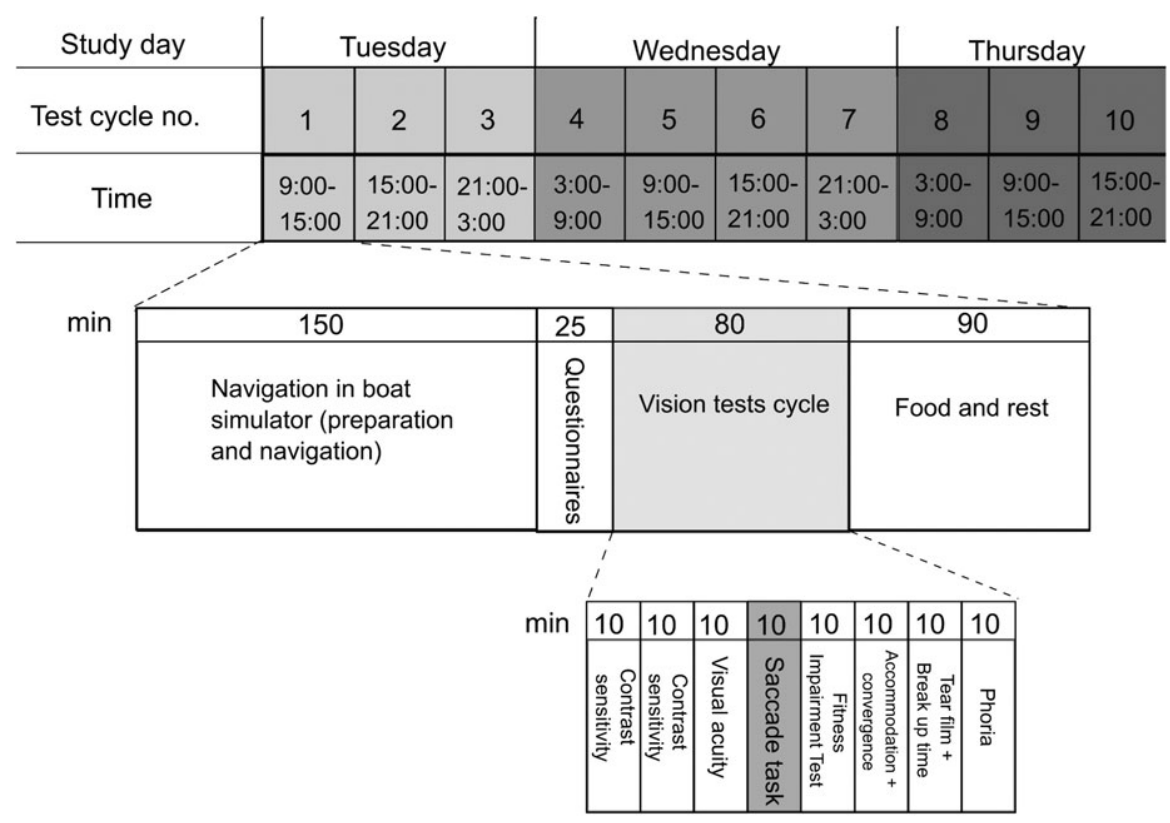

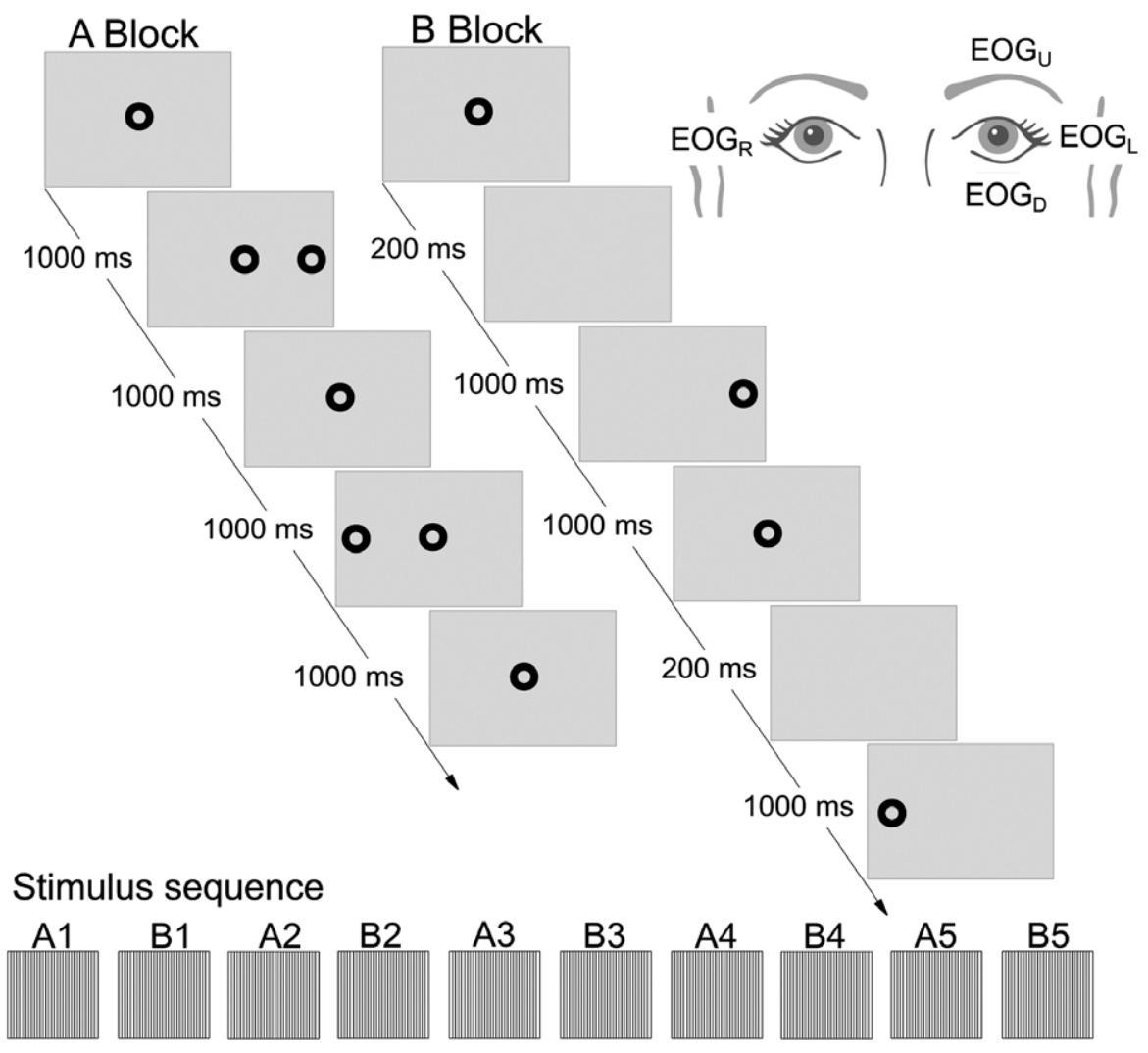

FIGURE 2 Electrode placement, saccade task and stimulus sequence. Electro-oculography (EOG) was measured with four AgAg-Cl electrodes placed at the outer canthi of both eyes (EOG,$\left.E O G_{L}\right)$, as well as above and below the left eye (EOGU, EOG $)$. The measurements were performed using bipolar coupling and the electrodes were grounded to the left mastoid (M2), behind the left ear (not visible in the figure). The saccade task consisted of alternating overlap (A) and gap (B) blocks. In the A block the central fixation point (a black doughnut) was visible all the time. The task sequence started with the central fixation point. After $1000 \mathrm{~ms}$ the target stimulus (a black doughnut) appeared on either the left or the right side of the screen (horizontal saccades). The target stimulus disappeared after 1000 ms and the next trial started with a central fixation point. In the B block the fixation point disappeared $200 \mathrm{~ms}$ before the target stimulus appeared. The horizontal saccades were presented in 20-saccade blocks and there were 5-s rest pauses between the blocks (stimulus sequence). One 20saccade block lasted $40 \mathrm{~s}$ in the A block and $44 \mathrm{~s}$ in the B block. In each 8-min measurement session, 200 saccade stimuli, 100 per condition ( $A$ or $B$ ), were presented 
sleeping habits were screened using the Composite Morningness Questionnaire (Smith, Reilly, \& Midkiff, 1989) and Epworth Sleepiness Scale (Johns, 1991). None of these indicated mental health problems, sleep disorders or abnormal sleep habits, and the participants were on mediation. Two participants used corrective lenses for myopia. During the study contact lens users wore glasses. The participants reported normal sleep length (before working days: mean, 6.9; SD, 0.7; range, 6-8 hr).

This study adhered to the Declaration of Helsinki and all participants gave written informed consent. A physician was on call on site throughout the sleep deprivation periods. The study protocol was approved by the Regional Committee for Medical Research Ethics, Western Norway, and the Norwegian Social Science Data Services. The participants were paid for their participation.

\subsection{Study design}

Eye movement measures were conducted as part of a larger research project in which the effect of sleep deprivation on performance in two high-speed navigation systems was studied (Gould et al., 2009). The study was carried out in ship simulators at the Naval Academy, Bergen. Measurements were made during two separate study weeks, each comprising $60 \mathrm{hr}$ of sleep deprivation. A 10week washout period between the study weeks eliminated carryover effects. Eye movements were measured in eight participants during the first measurement week. Five participated in both measurement weeks. Two weeks before start of measurements the participants received a letter with detailed information about the study, together with an Actigraph (ActiwatchTM, Cambridge Neurotechnology Inc., Cambridge, UK) and a sleep diary. They were instructed to go to bed between 23:00 and 24:00 hours, and to wake up between 07:00 and 08:00 hours on the last 7 days before the study. They were also requested to consume no alcoholic beverages $48 \mathrm{hr}$ prior to study start, as well as to drink no caffeinated beverages on the morning of the first day of the study.

On the first study day, participants arrived at 08:00 hours and the first navigation session started at 09:00 hours (Figure 1). A single navigation session lasted $2.5 \mathrm{hr}$, including preparation and rest breaks. After navigation, participants filled in questionnaires on PDAs (portable digital assistants). Next there was an 80 -min period where the participants underwent eight vision tests in a darkened test room ( $<5 \mathrm{~cd}$ ), including the saccade tasks measured with EOG, and the fitness impairment tester (Gould et al., 2009; Hirvonen et al., 2010) and contrast vision (Koefoed, Aßmus, Gould, Hövding, \& Moen, 2015). The test cycle (preparation-simulator navigation sessionquestionnaires - vision tests) was repeated 10 times. Each test cycle, including breaks, lasted $6 \mathrm{hr}$. At the completion of each test cycle, the participants were allowed $90 \mathrm{~min}$ to eat and rest, but not to sleep, before the next test cycle started. Participants who showed signs of falling asleep were prompted to stay awake by a research assistant who was observing the subjects to ensure that they did not nap. The same test cycle was followed throughout the study. The eye movement data from the first nine test cycles are presented in this article, because the saccade task measured with EOG was not measured during the 10th test cycle as the participants were too tired to carry out the saccade task.

The participants were allowed to use caffeine and tobacco to emulate realistic operation conditions. The use was limited to the number of units that each participant reported that he consumed during an ordinary workday (this information was obtained at the time of recruitment). Caffeine units were administered in the form of 4-g instant coffee sachets. None of the participants smoked, but one used smoke-free tobacco during the measurements.

The saccade task was administered using the presentation software (Neurobehavioural Systems, Albany, CA, USA, version 9.70). The EOG signal was measured with an Embla A10 device (Medcare, Reykjavik, Iceland) at $200 \mathrm{~Hz}$ sampling rate and $0.5-90 \mathrm{~Hz}$ bandwidth. Horizontal and vertical EOG were measured with four $\mathrm{AgAg}-\mathrm{Cl}$ electrodes (Technomed Europe, Maastricht, the Netherlands) placed at the outer canthi of both eyes, as well as above and below the left eye. The measurements were performed using bipolar coupling and electrodes were grounded to the left mastoid (M2) (Figure 2).

The participants sat in a chair at $70 \mathrm{~cm}$ distance from the computer screen. The distance was confirmed before every measurement. Participants were instructed to sit still, avoid blinking and to look at the location of the central fixation point (a black doughnut) until the target stimulus (a black doughnut) appeared, after which they were supposed to move their gaze as quickly as possible to the target stimulus. When the stimulus disappeared, they were instructed to move their gaze back to the central fixation point. The amplitude of horizontal saccades was $10^{\circ}$ (degrees of visual angle), whereas the size of the fixation point and the target stimulus was $1^{\circ}$. The saccade task consisted of

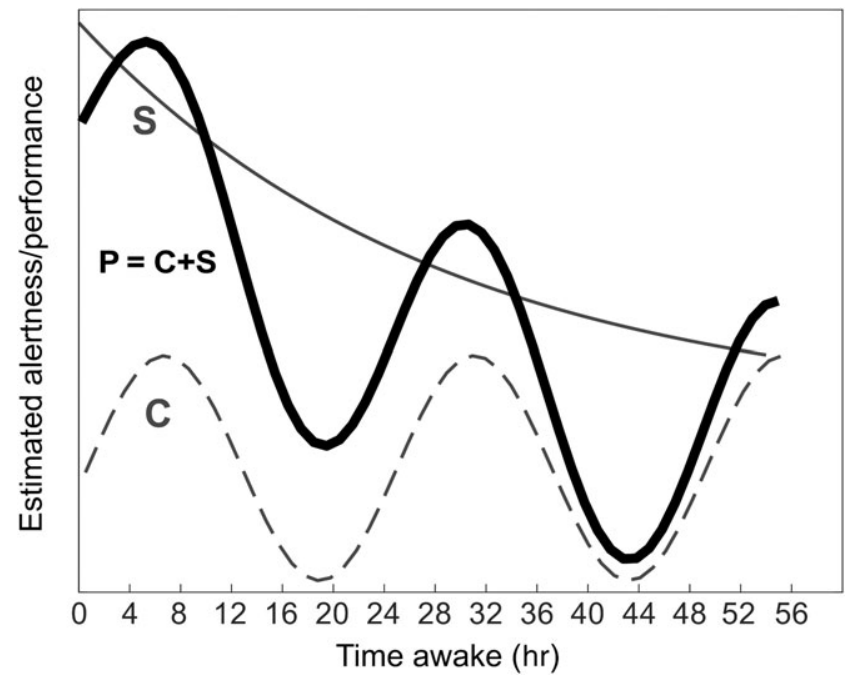

FIGURE 3 Schematic figure of two components, C and S, of the three-process model (Åkerstedt \& Folkard, 1997). The model comprises three components $\mathrm{C}, \mathrm{S}$ and $\mathrm{W}$. Here, the $\mathrm{C}$ and $\mathrm{S}$ processes are presented. The sinusoidal C-process (grey dashed line) represents sleepiness due to circadian influence (wake up at 07:00 hours). The exponential S-process (grey solid line) represents time lapsed since awakening (homeostasis). The estimated performance/ alertness $(P)$ is the sum of the $S$ and $C$ processes (black line) 


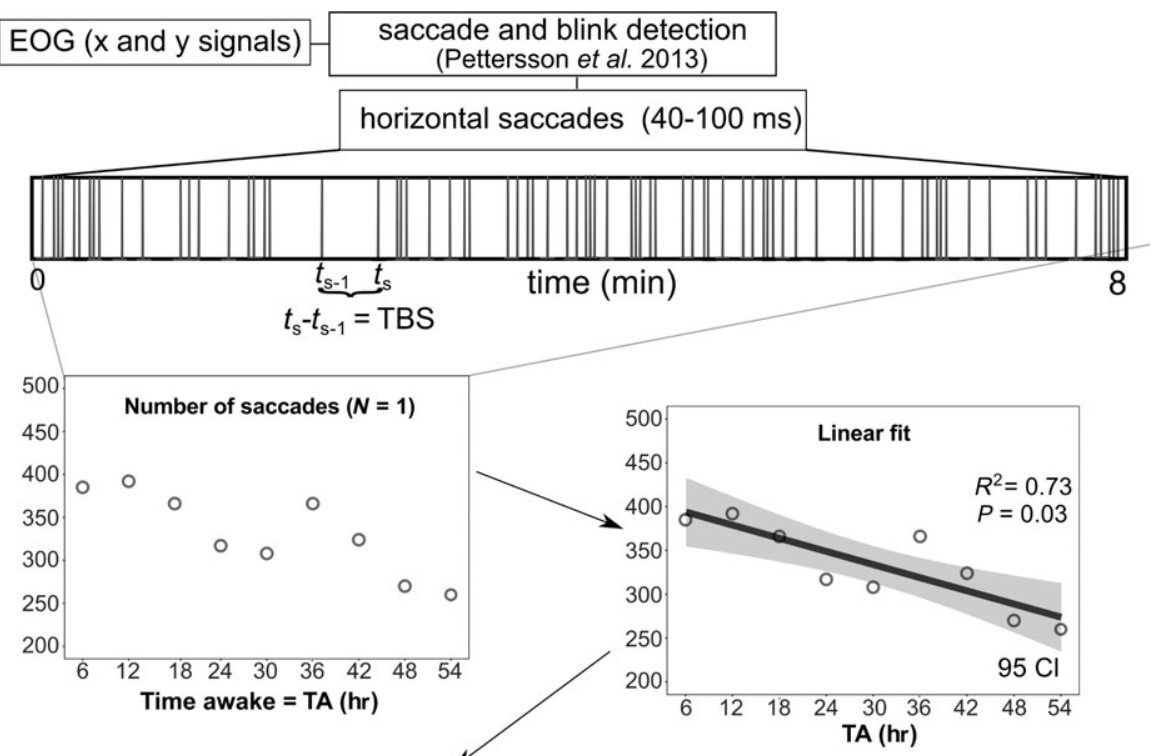

FIGURE 4 Analysis chain. The number of saccades for each participant was measured in the saccade task using electro-oculography (EOG). The linear model was fitted to examine the linearity of the decrease in the number of saccades. To improve the linear fit the three-process model of alertness was fitted to the data. After fitting, the $\mathrm{C}$ component was removed from the measured data to allow us to examine the exponential function without interference from the sinusoidal component. TPMA, three-process model of alertness
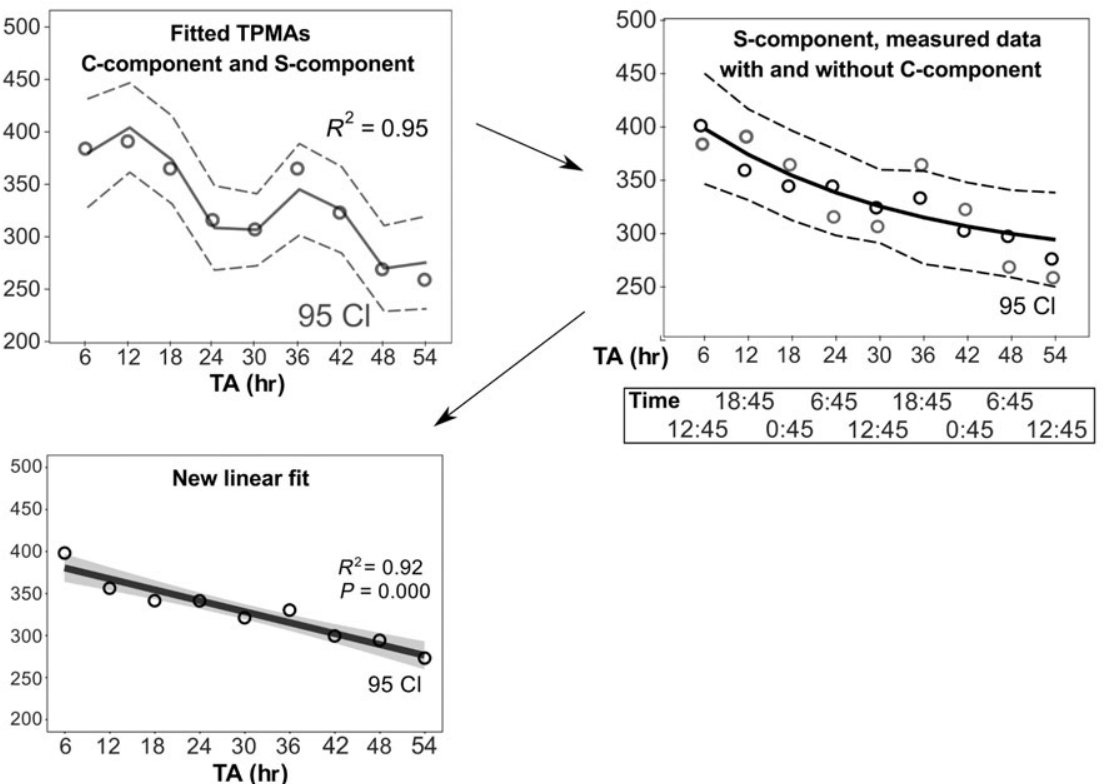

alternating A (overlap stimulus) and B (gap stimulus) blocks (Fischer, Gezeck, \& Hartnegg, 1997). Both paradigms and the saccade task sequence are depicted in Figure 2.

\section{3 | Modelling the circadian rhythm}

The three-process model of alertness (Åkerstedt \& Folkard, 1997) was used to model the circadian and homeostatic components of the saccade task performance. The model comprises three components: a circadian process (C), a homeostatic process that starts at awakening (S) and sleep inertia (W). We used only S and C, because participants were not allowed to sleep during the study (Figure 3).

The C-process represents alertness due to the circadian influence and has a sinusoidal-like shape (Equation 1). The S-process is an exponential function that represents the time passed since waking up (homeostasis) (Equation 2). The $\mathrm{C}$ and $\mathrm{S}$ components are added
(Equation 3) to predict $(\mathrm{P})$ alertness or performance in a monotonous task.

$$
\mathrm{S}=\left(\mathrm{S}_{\mathrm{a}}-\mathrm{L}\right) \mathrm{e}^{-0.0353 \mathrm{t}_{2}}+\mathrm{L}
$$

Here, $\mathrm{S}=$ homeostasis component (awake), $\mathrm{S}_{\mathrm{a}}=$ value of $\mathrm{S}$ at waking up, $\mathrm{L}=$ lower asymptote (the lowest value that the exponential function reaches) and $t_{2}=$ time since awakening.

$$
C=\operatorname{Mcos}\left(\left(t_{1}-p\right) \frac{\pi}{12}\right)
$$

where $\mathrm{C}=$ circadian component, $\mathrm{M}=$ amplitude of the circadian, $\mathrm{p}=$ acrophase $\rightarrow$ time-point when the circadian rhythm reaches its peak value (decimal hours) and $t_{1}=$ time of the day (decimal hours).

The alertness predictor $(P)$ is the sum of the $S$ and $C$ processes:

$$
\mathrm{P}=\mathrm{C}+\mathrm{S}=\mathrm{M} \cos \left(\left(\mathrm{t}_{1}-\mathrm{p}\right) \frac{\pi}{12}\right)+\left(\mathrm{S}_{\mathrm{a}}-\mathrm{L}\right) \mathrm{e}^{-0.0353 \mathrm{t}_{2}}+\mathrm{L}
$$

The three-process model was fit to the eye movement data using Matlab's fit function. The trust-region-reflective least squares 
algorithm was used for optimization and no starting points were given. After fitting, the C-process (circadian rhythm) was subtracted from the predictor $(P)$ and from the original number of saccades to get the estimate for time awake/sleep pressure (S). Confidence levels for estimated performance (fit) were determined by using Matlab's predint function with observational non-simultaneous bands. The 95\% confidence levels were estimated for the new observation by using fit and residuals.

\subsection{Traditional saccade task analysis}

The saccades have been analysed by comparing the participants' reaction to each saccade stimulus (altogether 200 stimuli per measurement) (event by event). The eye movements were extracted from the EOG signal by using a velocity threshold method and the EOG signal was calibrated before the measurement (described in detail in Hirvonen et al., 2010). Correctly executed saccades were responses that were along the same direction as the stimulus inside an 80-700 ms window after the stimulus appeared and for which the accuracy of the executed saccade (saccade gain = executed saccade amplitude/stimulus amplitude) was 0.5-1.5 (e.g. Gais et al., 2008). Trials including blinks, oblique saccades, omissions, direction errors, undershoot (gain $<0.5$ ), overshoot (gain $>1.5$ ) and anticipatory reaction $(<80 \mathrm{~ms}$ ) were classified as erroneous reactions. The data were defined as missing if there were less than five correctly performed saccades in the measurement session or if the calibration could not be done because of poor signal quality or not enough correctly executed saccades.

\subsection{Proposed new method for saccade task analysis: Number of saccades}

Our proposed analysis approach does not analyse saccades event by event. The method gives an estimation of performance by calculating the number of task-related horizontal saccades. Therefore, the proposed approach enables measurements without tight triggering between the saccade task and EOG signal. Figure 4 presents the analysis chain of the proposed method for saccade task analysis. First, the saccades (horizontal, vertical and oblique) and blinks were identified in the horizontal and vertical EOG signals by an auto-calibrating
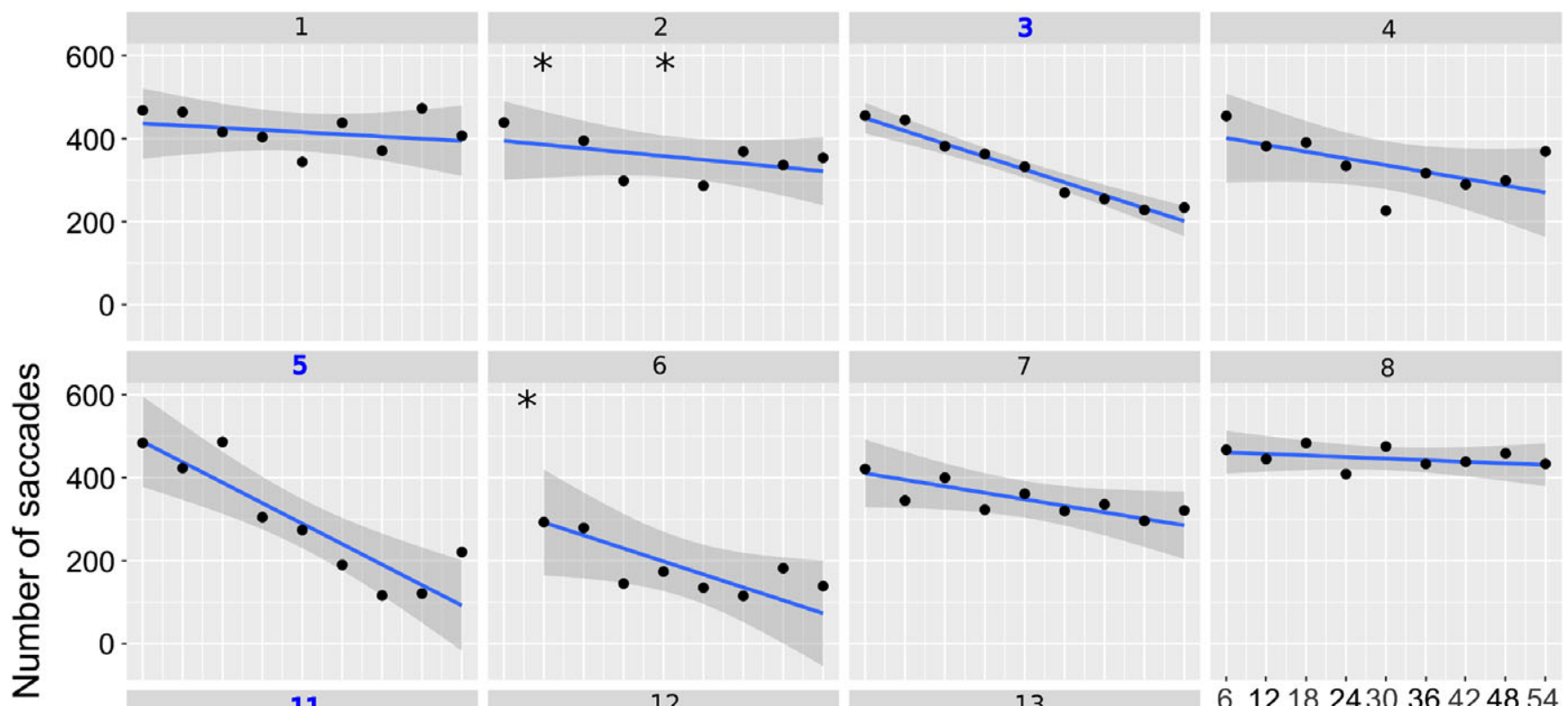

5

6

7
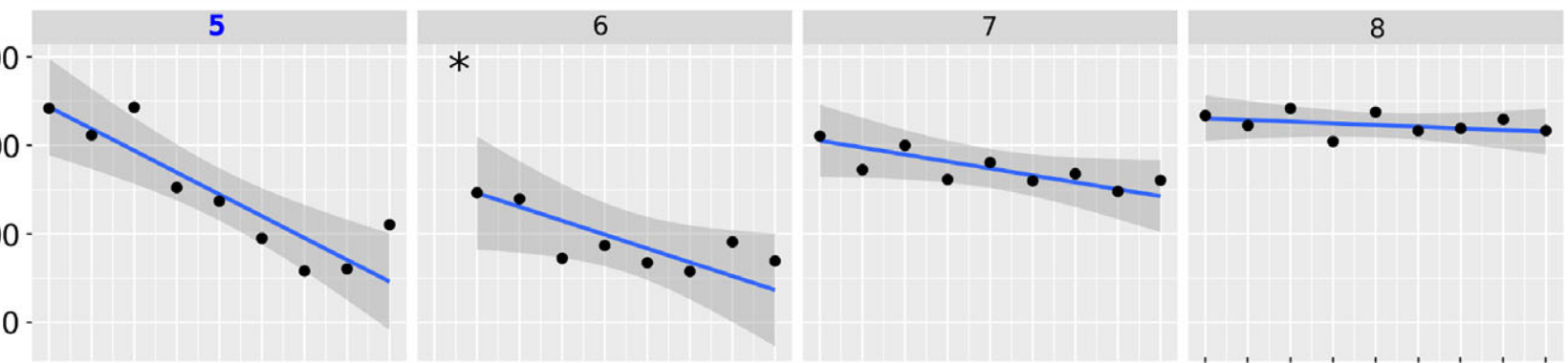

12
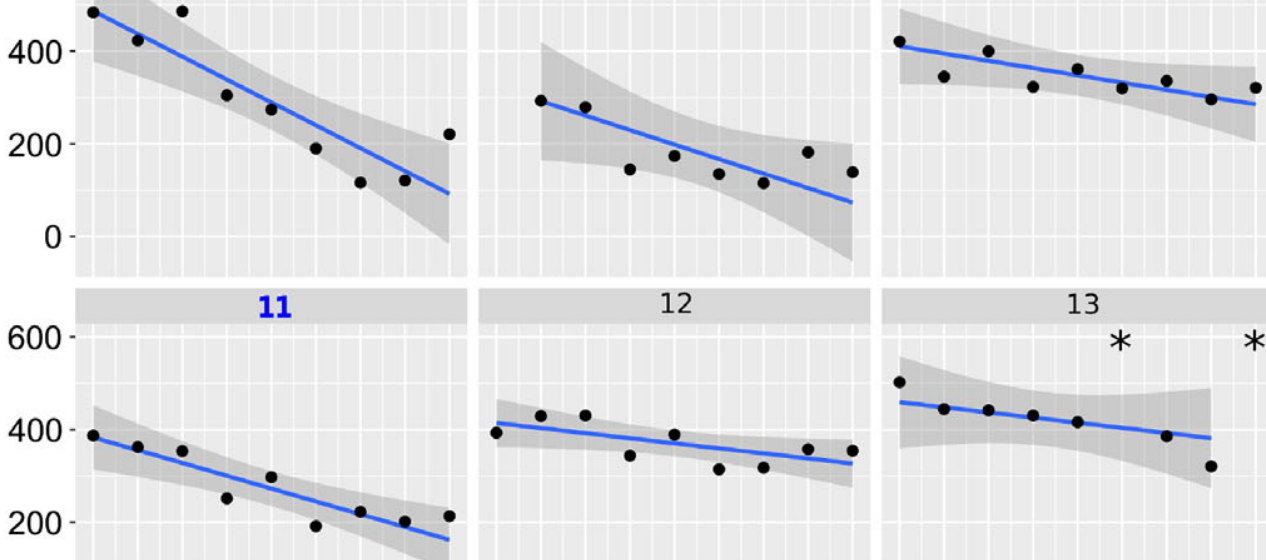

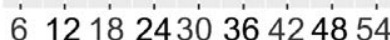
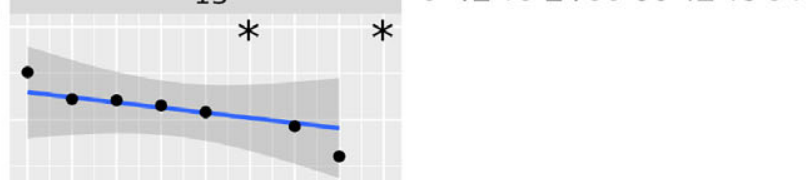

0

612182430364248546121824303642485461218243036424854

\section{Time awake (hr)}

FIGURE 5 Number of saccades as a function of time awake. The number of saccades as a function of time awake and estimated linear fits (blue line; grey areas denote $95 \%$ confidence level) for each participant. The caption above each plot represents the participant number; blue participant number indicates $p<0.05$ for the linear fit. Because of technical problems (e.g. loose electrodes) some measurements are missing; they are marked with a star 
The result of traditional saccade task analysis
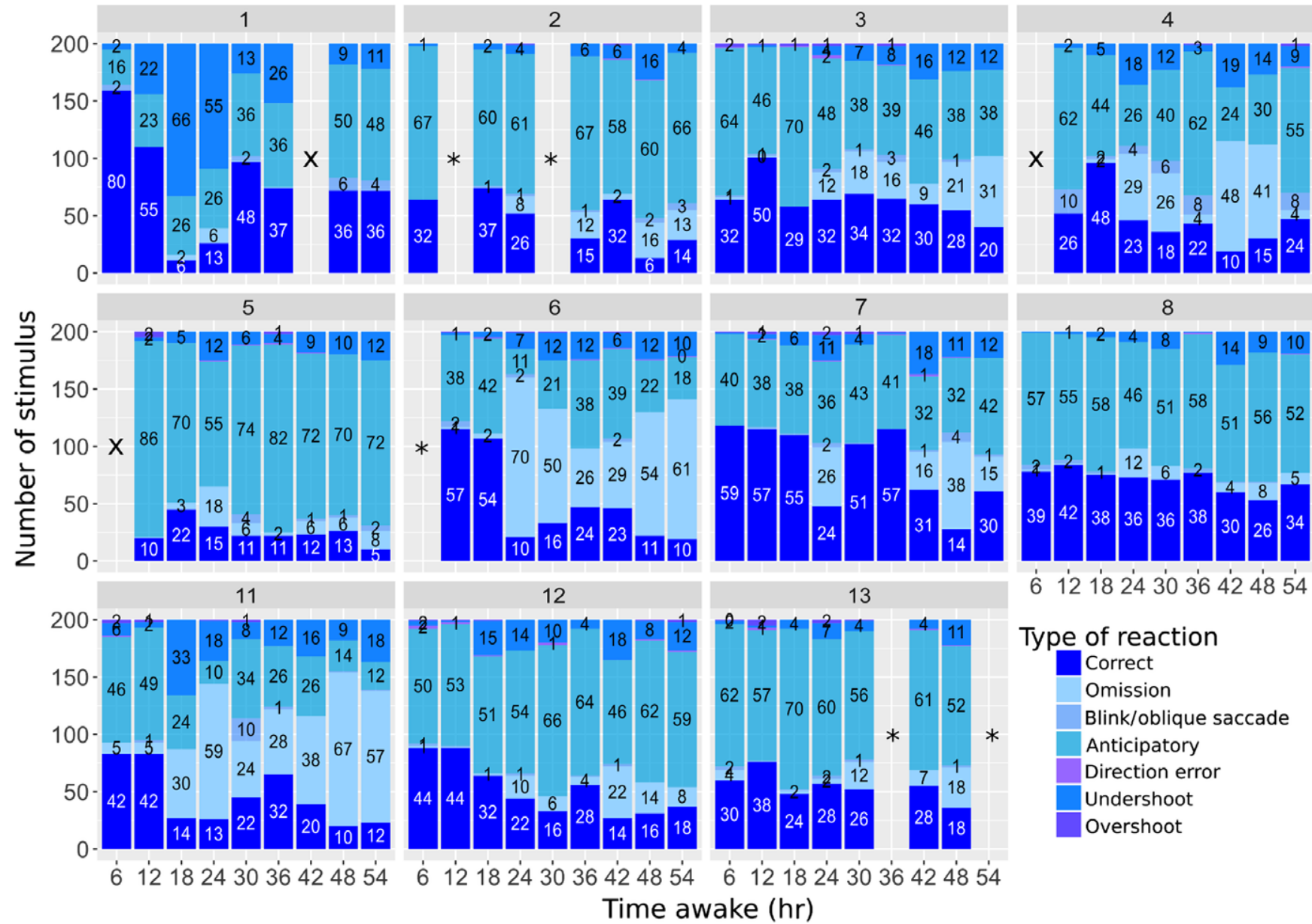

$6 \quad 1218243036424854$

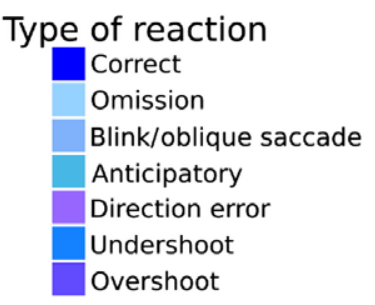

Time awake (hr)

FIGURE 6 Saccade task performance (traditional saccade task analyses). The result of the traditional saccade task analysis. Proportion of correctly executed saccades and different kinds of errors in each saccade task. The numbers on the coloured bar indicate the proportion of each response type to the saccade stimulus. The proportion of correctly executed saccades is marked with dark blue bars. The data were defined as missing if there were fewer than five correctly performed saccades in the measurement session or if the calibration could not be carried out because of poor signal quality or not enough correctly executed saccades (marked with a letter $\mathrm{x}$ ). Because of technical problems (e.g. loose electrodes) some measurements are missing; these are marked with a star

algorithm (Pettersson et al., 2013). Then data collected during the 5-s rest pauses were removed. Next blinks, vertical saccades, oblique saccades and horizontal saccades that lasted either $<40 \mathrm{~ms}$ or $>100 \mathrm{~ms}$ were removed. The durations of the $10^{\circ}$ horizontal saccades are between 43 and 59 ms (Bahill, Brockenbrough, \& Troost, 1981); therefore, the saccades that last 40 to $100 \mathrm{~ms}$ are possibly related to reactions to saccade task stimuli. The number of remaining saccades (after the described steps) represents the participant's performance in the saccade task. A simple linear regression model was fitted using the R Im function (qr method) to estimate the linearity of the decrease of the number of saccades as a function of time awake (Porcu et al., 1998).

\subsection{Time between saccades}

Time between saccades (TBS) was calculated from the saccade time series by subtracting the starting time of a saccade $\left(t_{s}\right)$ from the previous saccade starting time $\left(t_{\mathrm{s}-1}\right)$. The TBS values were used to investigate the task performance and individual differences. TBS values were also used to examine how the novel analysis compares with the traditional event by event method.

\section{3 | RESULTS}

\subsection{Number of saccades}

The number of saccades as a function of time awake for each participant $(n=11)$ is presented in Figure 5. The saccade task included 200 stimuli and 200 return saccades, which means that when the participant has performed the task correctly the number of saccades should be close to 400 . The simple linear fits were calculated for each participant to estimate the linearity of the decrease in the number of saccades as a function of time awake and to examine individual differences. The linear fit showed significant correlation 
between the number of saccades and time awake for three participants.

\section{2 | Traditional saccade task analysis}

Figure 6 shows the proportion of correctly executed saccades (dark blue bars) as well as different kinds of errors on an individual level as analysed using a traditional event by event analysis.

\section{3 | Time between saccades (TBS)}

Time between saccades values were calculated to examine individual differences in saccade task performance. Some participants exhibit bimodal TBS distributions, with peaks on both sides of $1 \mathrm{~s}$. If the participant performs the task correctly the TBS value should be approximately $1 \mathrm{~s}$. However, if the TBS value is much less than $1 \mathrm{~s}$ the participant probably made a corrective saccade right after the erroneous reaction (direction error, overshoot, undershoot). TBS values much larger than $1 \mathrm{~s}$ imply that the participant did not respond to the stimulus (omission). Based on these assumptions we divided the TBS values into three groups: early response $(<0.5 \mathrm{~s})$, normal responses $(0.5-1 \mathrm{~s})$ and late responses (>1.5 s) (Figure 7).

\subsection{Repeatability $(n=5)$}

Figure 8 shows the number of saccades in the first and second measurements of participants 2, 3, 5, 6 and 7. Correlations between the time series are calculated using cross-correlation (lag $=0$ ). The correlation values were between 0.62 and 0.96 (mean 0.79).

\section{The result of number of saccades -analysis}

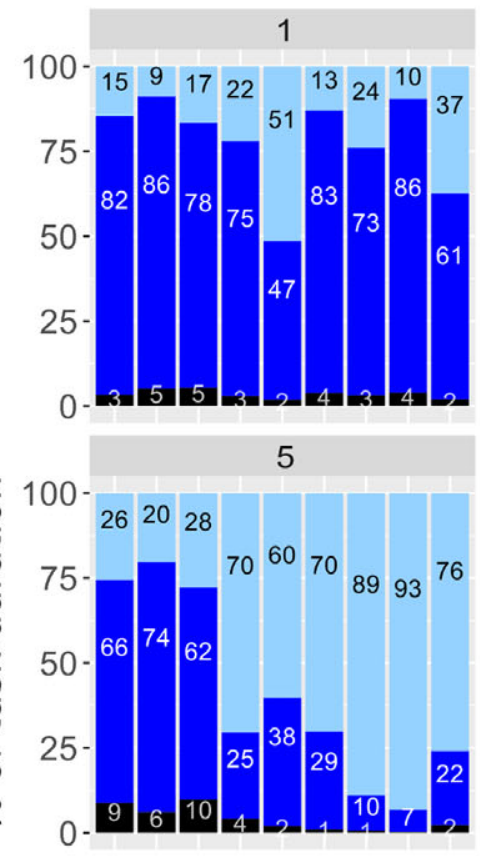

11

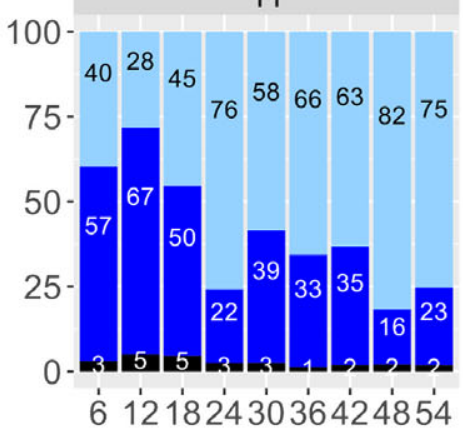

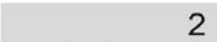

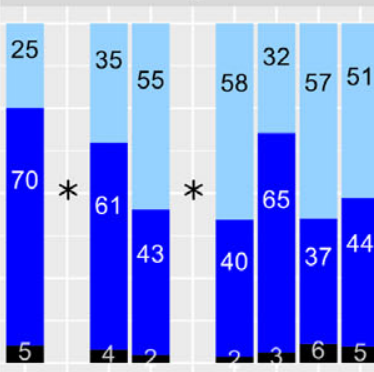

6

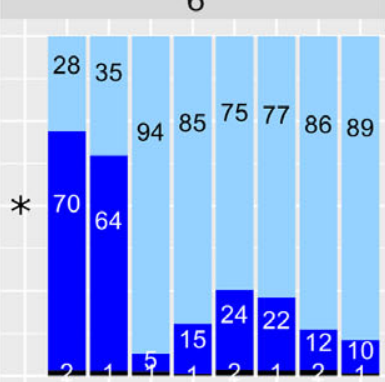

12

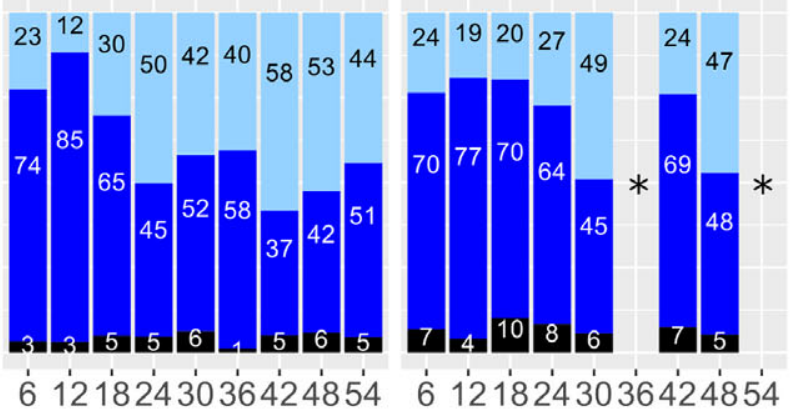

Time awake (hr)
3

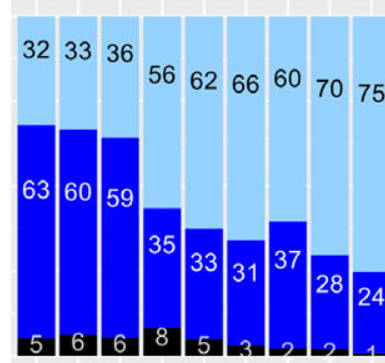

7

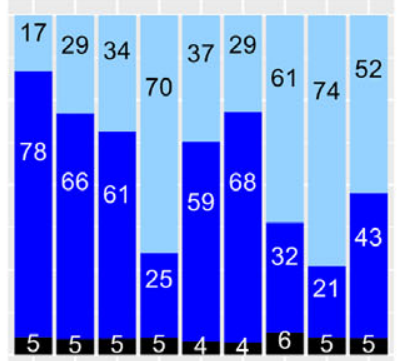

13

'่ 1่2182่
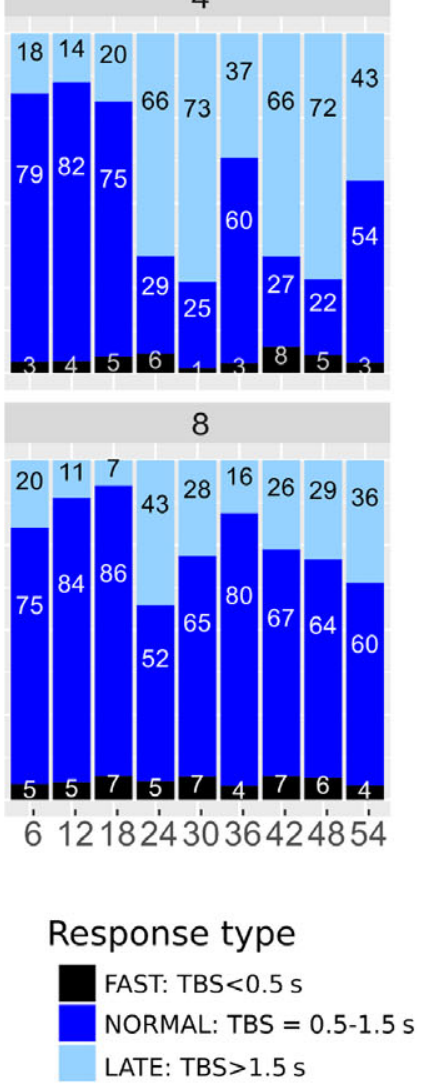

8

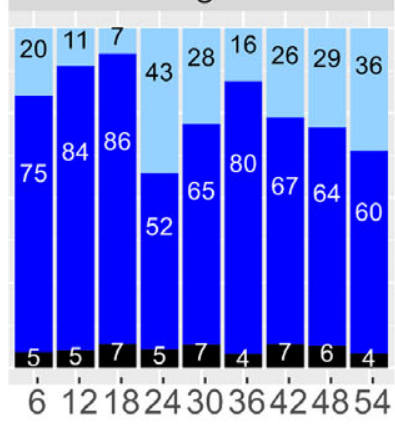

LATE: TBS $>1.5 \mathrm{~s}$

FIGURE 7 Saccade task performance (new method). The number of saccades determined using the time-between-saccades approach. The proportion of time (cumulative sum of time between saccades [TBS]) of fast $(<0.5 \mathrm{~s}$ ) (black), normal (0.5-1.5 s) (dark blue) and late ( $>1.5 \mathrm{~s})$ (light blue) TBS values for each participant. The caption above each plot represents the participant number. Because of technical problems (e.g. loose electrodes) some measurements are missing; these are marked with a star 


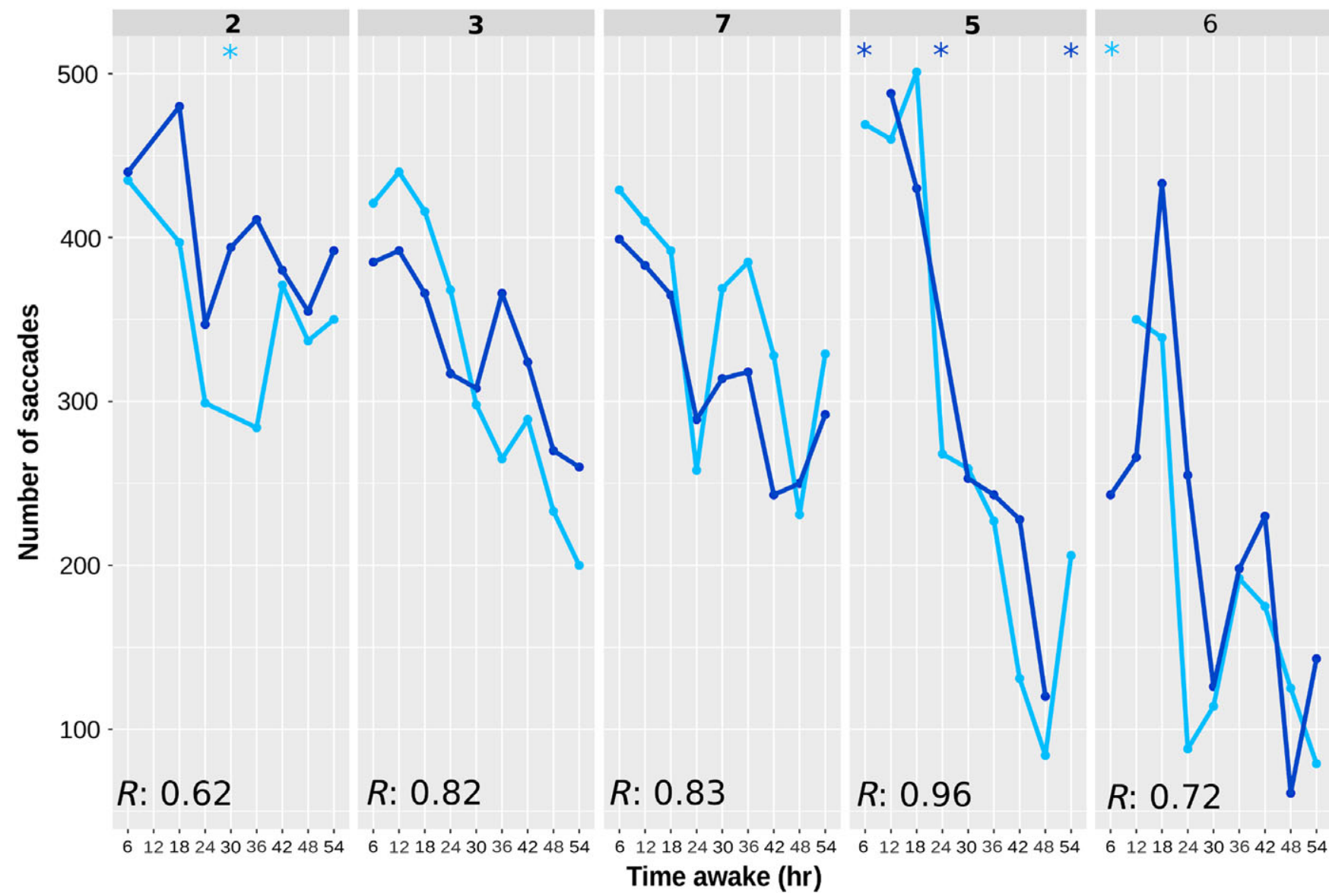

FIGURE 8 Repeatability $(n=5)$. The number of saccades recorded during the first measurement is shown in light blue, whereas the number of saccades obtained during the second measurement is indicated in blue. The correlation coefficient (R) is black. Missing values are marked with a star

\subsection{Modelling and removing the circadian component}

The three-process model of alertness (Åkerstedt \& Folkard, 1997) was used to model saccade task performance. We fitted the model's $\mathrm{C}$ and $\mathrm{S}$ components to the number of saccades and removed the $\mathrm{C}$ component from the fit model. Figure 9 presents the fit curves and the remaining $\mathrm{S}$ component. The goodness of the fit differs between the participants. The results of the linear fits after removing the $C$ component are presented in Figure 10. By removing the circadian component from the number of saccades the linear fit showed significant correlation between the number of saccades and time awake for six participants.

\section{DISCUSSION}

Prolonged time awake increases sleep pressure and sleepiness. We used an eye movement-based metrics as a way to estimate time awake by using data from our earlier study Hirvonen et al., 2010. The number of saccades during an 8-min saccade task including overlap and gap paradigms was recorded outside the laboratory using EOG. The measurements were made every $6 \mathrm{hr}$ until $54 \mathrm{hr}$ of time awake. As the time spent in the task affects sustained attention, the data from both overlap and gap paradigms were combined in this study.

Our results showed a decreasing trend between the number of saccades and prolonged time awake; the linear trend was significant for three out of 11 participants (Figure 5). Because the circadian rhythm affected the number of executed saccades (Figure 5), we fitted the three-process model of alertness (TPMA) and removed the circadian component (C-component) from the measured data (Figure 9). After removing the C-component, the linear model showed a significant trend for six out of 11 participants (Figure 10). Our result is in line with Porcu et al.'s group level analyses $(n=5)$. They reported that the saccade task error rate followed a linear trend during one night of sleep deprivation (Porcu et al., 1998).

Our results indicate that there is inter-individual variation in saccade task performance when sleep deprived (Figures 5-7). However, Figure 8 shows that performance is rather stable within individuals $(n=5)$. Similar results have been obtained with PVT and other cognitive and reaction-time tasks (Leproult et al., 2003; Van Dongen et al., 2004). Genetic factors may explain sleepiness-related inter-individual variations in neurobehavioural decrements (e.g. Goel, 2017; Kuna et al., 2012). There is evidence that phenotypic 

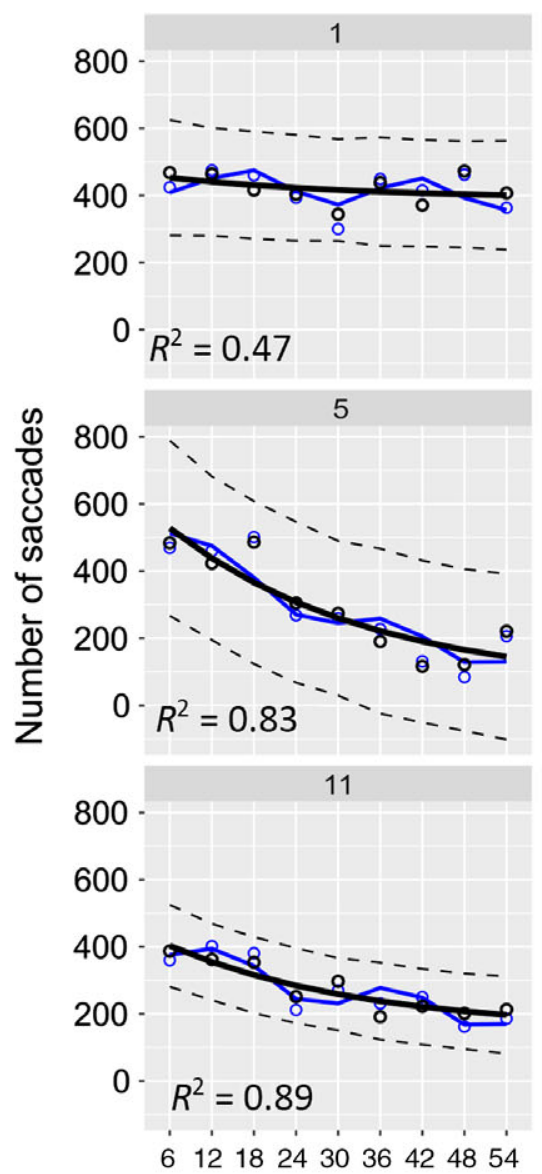
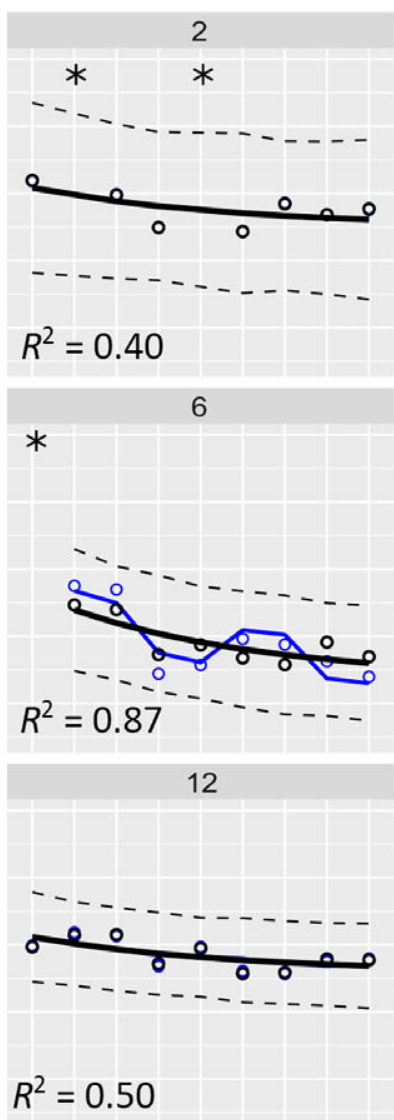

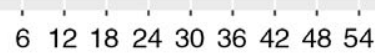
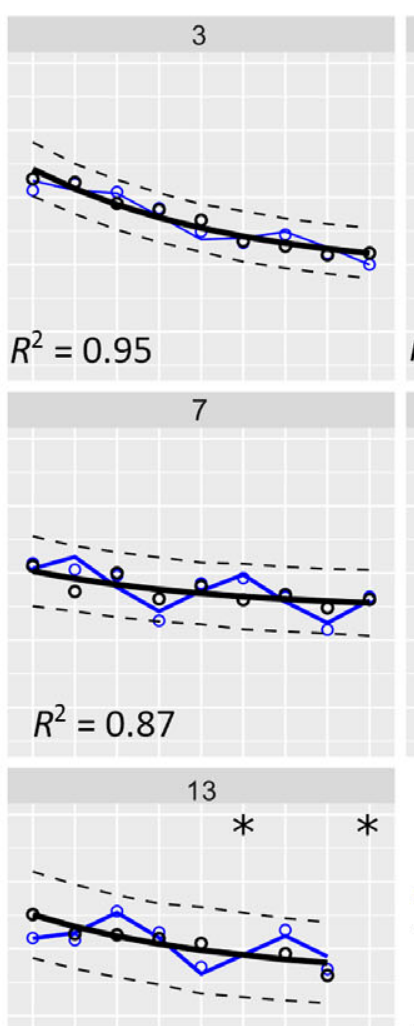

$R^{2}=0.87$

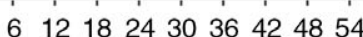
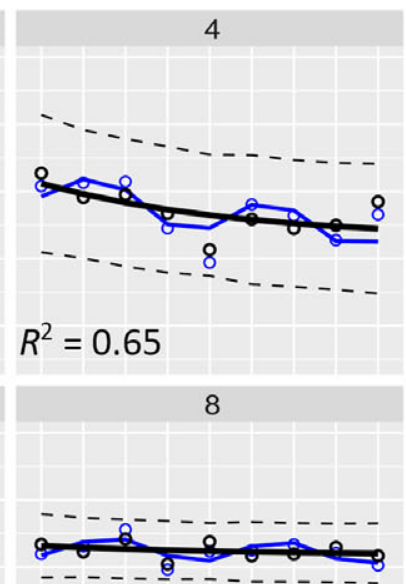

$R^{2}=0.68$

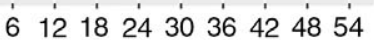

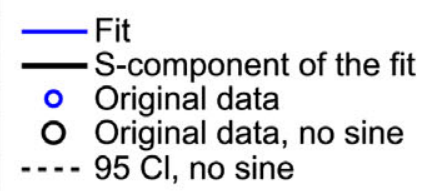

\section{Time awake (hr)}

FIGURE 9 Fit of S- and C-components of the three-process model of alertness (TPMA) model. A mathematically monotonous (here always decreasing) relation between time between saccades (TBS) and time awake for each participant (caption above each plot indicates participant number). Blue circles represent original data, the blue line is the result of fitting, the black line is the $\mathrm{S}$ component of the model and the black dashed line is a $95 \%$ confidence level for the $\mathrm{S}$ component. The black circles are the original data without the $\mathrm{C}$ component. The missing measurements are marked with a star, and $R^{2}$ values are shown for each fit

neurobehavioural responses to sleepiness are stable over long time intervals, even years (Dennis, Wohl, Selame, \& Goel, 2017; Rupp, Wesensten, \& Balkin, 2012).

In this study the decreasing number of saccades was a result of increasing TBS in the saccade task (Figure 6). TBS values were divided into fast, normal and late responses to permit linking the novel analysis method's results to those obtained with traditional saccade task analyses. Figures 6 and 7 show that TBS values exceeding $1.5 \mathrm{~s}$ were mostly due to omissions (lapses) and anticipatory reactions (false starts). Both omissions and commissions (e.g. reactions without stimulus or false starts) have been associated with sustained attention deficits caused by wake-state instability (e.g. Doran et al., 2001; Krause et al., 2017; Lim \& Dinges, 2008). The number of lapses (e.g. Van Dongen \& Dinges, 2005) and false starts (Basner et al., 2015) has been reported to increase when measured with PVT during prolonged wakefulness. Moreover, increasing homeostatic sleep drive has been reported to increase the number of commissions and omissions in saccade tasks, suggesting failures in sustaining attention (Wachowicz et al., 2015).
In saccade task studies using event by event analysis, decrement of speed parameters (saccade peak velocity and latency) has been reported in sleep deprivation (e.g. Ahlstrom et al., 2013; De Gennaro et al., 2000; Ferrara et al., 2000; Fimm \& Blankenheim, 2016; Fransson et al., 2008; Hirvonen et al., 2010; Zils et al., 2005), whereas saccade accuracy is affected less frequently (Bocca \& Denise, 2006; Fransson et al., 2008; Porcu et al., 1998; Zils et al., 2005). The event by event analyses show (Figure 6) large individual differences between the subjects even in the first measurement (e.g. in the number of correctly executed saccades or anticipatory responses). Moreover, increasing sleep pressure affects the performance of participants differently: in some individuals saccades start to undershoot, whereas in others the number of anticipatory responses or omissions increases. The individual variability in performance between subjects may explain some inconsistency in the earlier findings (e.g. related to saccade accuracy).

Mathematical models of alertness have been used to model lapses in performing the PVT task. Both the two-process model of alertness (Achermann \& Borbély, 2003) and TPMA have been 


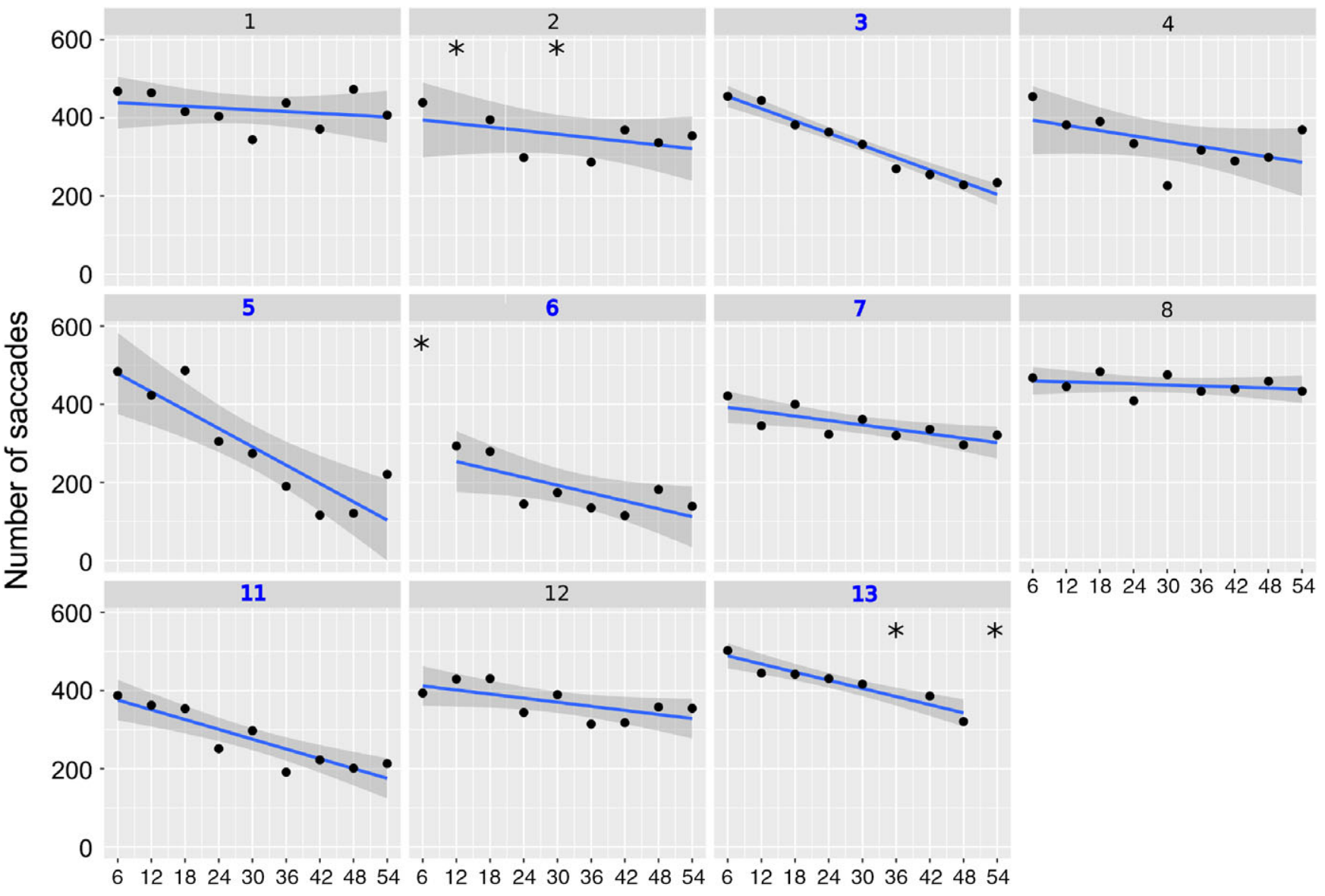

Time awake (hr)

FIGURE 10 Number of saccades as a function of time awake after removing the C-component. The number of saccades after removing the C-component as a function of time awake, and linear fits (blue line; grey areas denote $95 \%$ confidence level) for each participant. The caption above each plot represents the participant number; the blue participant number indicates $p<0.05$ for the linear fit. The missing values are marked with a star

reported to correlate with the number of PVT lapses (Van Dongen, 2004). We used TPMA because it was developed to also model neurobehavioural functions and because it is widely used in sleep deprivation studies (Achermann \& Borbély, 2003).

Saccades were detected with an automated algorithm (Pettersson et al., 2013) and only horizontal saccades that lasted $40 \mathrm{~ms}$ to $100 \mathrm{~ms}$, and thus infer reactions to task stimuli, were analysed. This differs from traditional laboratory studies where saccade reactions are analyzed event by event in the different saccade paradigms (overlap and gap). Our aim was to take one step closer to on-site measurements. This approach does not require time synchrony (between EOG signal and saccade task), making the implementation easier in field settings.

Sixty hours of sleep deprivation enabled us to study eye movements for almost three 24-hr cycles of circadian rhythm. Our measurements were made every sixth hour. More accurate modelling of the circadian rhythm requires more frequent measurements. This could potentially decrease the confidence levels and make time awake approximation more accurate. We studied a selected population of marine soldiers who were highly motivated to do their best in every situation and who were used to staying awake for long periods of time. Individual variability in the general population should be studied next.

The decrease in number of saccades with prolonged sleep deprivation varied between individuals but was rather stable within an individual. Because of individual task performance differences, the current system needs personal calibration before actual overall time awake measurements. More research is needed to study individual differences, to optimize saccade task parameters (e.g. duration, number of stimuli and the saccade task paradigm) and to make the calibration procedure shorter and more practical.

Our current results imply that eye movement-based measurements provide a potentially useful tool for measuring prolonged time awake outside the laboratory. The data of every participant show a decreasing trend between number of saccades and time awake, even though the study was designed to preserve realism: the participants were allowed to use caffeine and smokeless tobacco, and the eye movement analyses were carried out without tight triggering. Applications for such an estimate of time awake range from critical safety work, shift work and global work across time zones to everyday 
activities and health-related problems. Increases in sleepiness and fatigue caused by prolonged time awake result in psychomotor and attentional problems, thus elevating the risk of errors and accidents. A system that objectively estimates overall time awake can provide early warnings and help people find a balance between activity and rest.

\section{ACKNOWLEDGEMENTS}

This study was supported by the Seamless Patient Care project (Tekes-the Finnish Funding Agency for Technology and Innovation, grant 1939/31/2015) and Academy of Finland (decision 286154). We thank Jussi Virkkala, Kristian Lukander and Axi Holmström for their valuable discussions and comments.

\section{CONFLICT OF INTERESTS}

All authors declare no conflict of interests.

\section{AUTHOR CONTRIBUTIONS}

KP planned the eye movement measurement set-up and conducted the measurements, carried out the analyses and wrote the manuscript. KG planned and supervised the sleep deprivation study, performed the experiments and reviewed the manuscript for scientific content. AT gave guidance on data analysis and interpretation of the results and took part in writing the manuscript. EH and KM gave guidance on data analyses and interpretation of the results, supervised the writing and reviewed the manuscript for scientific content.

\section{ORCID}

Kati Pettersson (iD http://orcid.org/0000-0003-3976-0042

\section{REFERENCES}

Achermann, P., \& Borbély, A. (2003). Mathematical models in sleep deprivation. Frontiers in Bioscience, 8, 683-693.

Ahlstrom, C., Nyström, M., Holmqvist, K., Fors, C., Sandberg, D., Anund, A., ... Åkerstedt, T. (2013). Fit-for-duty test for estimation of drivers' sleepiness level: Eye movements improve the sleep/wake predictor. Transportation Research Part C: Emerging Technologies, 26, 20-32. https://doi.org/10.1016/j.trc.2012.07.008

Åkerstedt, T. (2000). Consensus statement: Fatigue and accidents in transport operations. Journal of Sleep Research, 9, 395-395. https://d oi.org/10.1046/j.1365-2869.2000.00228.x

Åkerstedt, T., \& Folkard, S. (1997). The three-process model of alertness and its extension to performance, sleep latency, and sleep length. Chronobiology International, 14, 115-123. https://doi.org/10.3109/ 07420529709001149

Bahill, A. T., Brockenbrough, A., \& Troost, B. T. (1981). Variability and development of a normative data base for saccadic eye movements. Investigative Ophthalmology \& Visual Science, 21, 116-125.

Basner, M., Mcguire, S., Goel, N., Rao, H., \& Dinges, D. F. (2015). A new likelihood ratio metric for the psychomotor vigilance test and its sensitivity to sleep loss. Journal of Sleep Research, 24, 702-713. https://doi.org/10.1111/jsr.12322

Bioulac, S., Franchi, J. A. M., Arnaud, M., Sagaspe, P., Moore, N., Salvo, F., \& Philip, P. (2017). Risk of motor vehicle accidents related to sleepiness at the wheel: A systematic review and meta-analysis. Sleep, 40, 1-10. https://doi.org/10.1093/sleep/zsx134

Bocca, M.-L., \& Denise, P. (2006). Total sleep deprivation effect on disengagement of spatial attention as assessed by saccadic eye movements. Clinical Neurophysiology, 117, 894-899. https://doi.org/10. 1016/j.clinph.2006.01.003

Casarotti, M., Lisi, M., Umiltà, C., \& Zorzi, M. (2012). Paying attention through eye movements: A computational investigation of the premotor theory of spatial attention. Journal of Cognitive Neuroscience, 24, 1519-1531. https://doi.org/10.1162/jocn_a_00231

Corbetta, M., \& Shulman, G. L. (2002). Control of goal-directed and stimulus-driven attention in the brain. Nature Reviews Neuroscience, 3, 215-229. https://doi.org/10.1038/nrn755

Dawson, D., \& Reid, K. (1997). Fatigue, alcohol and performance impairment. Nature, 388, 235-235. https://doi.org/10.1038/40775

De Gennaro, L., Ferrara, M., Curcio, G., \& Bertini, M. (2001). Visual search performance across $40 \mathrm{~h}$ of continuous wakefulness: Measures of speed and accuracy and relation with oculomotor performance. Physiology \& Behavior, 74, 197-204. https://doi.org/10.1016/ S0031-9384(01)00551-0

De Gennaro, L., Ferrara, M., Urbani, L., \& Bertini, M. (2000). Oculomotor impairment after 1 night of total sleep deprivation: A dissociation between measures of speed and accuracy. Clinical Neurophysiology, 111, 1771-1778. https://doi.org/10.1016/S1388-2457(00)00393-X

Dennis, L. E., Wohl, R. J., Selame, L. A., \& Goel, N. (2017). Healthy adults display long-term trait-like neurobehavioral resilience and vulnerability to sleep loss. Scientific Reports, 7, 1-10. https://doi.org/10.1038/ s41598-017-14006-7

Doran, S., Van Dongen, H. P. A., \& Dinges, D. F. (2001). Sustained attention performance during sleep deprivation evidence of state instability. Archives Italiennes De Biologie, 139, 253-267.

Durmer, J., \& Dinges, D. F. (2005). Neurocognitive consequences of sleep deprivation. Seminars in Neurology, 25, 117-129. https://doi.org/10. 1055/s-2005-867080

Ferrara, M., De Gennaro, L., \& Bertini, M. (2000). Voluntary oculomotor performance upon awakening after total sleep deprivation. Sleep, 23, 1-11. https://doi.org/10.1093/sleep/23.6.1g

Fimm, B., \& Blankenheim, A. (2016). Effect of sleep deprivation and low arousal on eye movements and spatial attention. Neuropsychologia, 92, 115-128. https://doi.org/10.1016/j.neuropsychologia.2016.03. 021

Fischer, B., Gezeck, S., \& Hartnegg, K. (1997). The analysis of saccadic eye movements from gap and overlap paradigms. Brain Research Protocols, 2, 47-52. https://doi.org/10.1016/S1385-299X(97)00027-5

Fransson, P.-A., Patel, M., Magnusson, M., Berg, S., Almbladh, ... S. (2008). Effects of 24-hour and 36-hour sleep deprivation on smooth pursuit and saccadic eye movements. Journal of Vestibular Research, 18, 209-222.

Gais, S., Köster, S., Sprenger, A., Bethke, J., Heide, W., \& Kimmig, H. (2008). Sleep is required for improving reaction times after training on a procedural visuo-motor task. Neurobiology of Learning and Memory, 90, 610-615. https://doi.org/10.1016/j.nlm.2008.07.016

Goel, N. N. (2017). Effects and biomarkers of sleep loss in healthy adults. Current Neurology and Neuroscience Reports, 17. https://doi.org/10. 1007/s11910-017-0799-x

Gonçalves, M., Amici, R., Lucas, R., Åkerstedt, T., Cirignotta, F., Horne, J., ... Peigneux, P. (2015). Sleepiness at the wheel across Europe: A survey of 19 countries. Journal of Sleep Research, 24, 242-253. https://d oi.org/10.1111/jsr.12267

Gould, K. S., Hirvonen, K., Koefoed, V. F., RØed, B. K., Sallinen, M., Holm, A., ... Moen, B. E. (2009). Effects of 60 hours of total sleep 
deprivation on two methods of high-speed ship navigation. Ergonomics, 52, 1469-1486. https://doi.org/10.1080/ 00140130903272611

Grace, P. M., Stanford, T., Gentgall, M., \& Rolan, P. E. (2010). Utility of saccadic eye movement analysis as an objective biomarker to detect the sedative interaction between opioids and sleep deprivation in opioid-naive and opioid-tolerant populations. Journal of Psychopharmacology, 24, 1631-1640. https://doi.org/10.1177/ 0269881109352704

Hirvonen, K., Puttonen, S., Gould, K., Korpela, J., Koefoed, V. F., \& Müller, K. (2010). Improving the saccade peak velocity measurement for detecting fatigue. Journal of Neuroscience Methods, 187, 199-206. https://doi.org/10.1016/j.jneumeth.2010.01.010

Johns, M. W. (1991). A new method for measuring daytime sleepiness: The Epworth sleepiness scale. Sleep, 14, 540-545. https://doi.org/10. 1093/sleep/14.6.540

Johns, M. W., Chapman, R., Crowley, K., \& Tucker, A. (2008). A new method for assessing the risks of drowsiness while driving. Somnologie - Schlafforschung Und Schlafmedizin, 12, 66-74. https://doi.org/10. 1007/s11818-008-0330-3

Koefoed, V. F., Aßmus, J., Gould, K. S., Hövding, G., \& Moen, B. E. (2015). Contrast sensitivity and the effect of 60-hour sleep deprivation. Acta Ophthalmologica, 93, 284-288. https://doi.org/10.1111/ aos.12536

Krause, A. J., Simon, E. B., Mander, B. A., Greer, S. M., Saletin, J. M., Goldstein-Piekarski, A. N., \& Walker, M. P. (2017). The sleep-deprived human brain. Nature Reviews Neuroscience, 18, 404-418. https://doi. org/10.1038/nrn.2017.55

Kuna, S. T., Maislin, G., Pack, F. M., Staley, B., Hachadoorian, R., Coccaro, E. F., \& Pack, A. I. (2012). Heritability of performance deficit accumulation during acute sleep deprivation in twins. Sleep, 1223-1233. https://doi.org/10.5665/sleep.2074

Lee, J., Manousakis, J., Fielding, J., \& Anderson, C. (2015). Alcohol and sleep restriction combined reduces vigilant attention, whereas sleep restriction alone enhances distractibility. Sleep, 38, 765-775. https://doi.org/10.5665/sleep.4672

Leproult, R., Colecchia, E. F., Berardi, A. M., Stickgold, R., Kosslyn, S. M., \& Van Cauter, E. (2003). Individual differences in subjective and objective alertness during sleep deprivation are stable and unrelated. American Journal of Physiology-Regulatory, Integrative and Comparative Physiology, 284, R280-R290. https://doi.org/10.1152/ajpregu.00197. 2002

Lim, J., \& Dinges, D. F. (2008). Sleep Deprivation and Vigilant Attention. Annals of the New York Academy of Sciences, 1129, 305-322.

Pettersson, K., Jagadeesan, S., Lukander, K., Henelius, A., Ha eggström, E., \& ... K. (2013). Algorithm for automatic analysis of electro-oculographic data. BioMedical Engineering OnLine, 12, 110. https://doi.org/ 10.1186/1475-925X-12-110

Porcu, S., Ferrara, M., Urbani, L., Bellatreccia, A., \& Casagrande, M. (1998). Smooth pursuit and saccadic eye movements as possible indicators of nighttime sleepiness. Physiology \& Behavior, 65, 437443. https://doi.org/10.1016/S0031-9384(98)00181-4

Rupp, T. L., Wesensten, N. J., \& Balkin, T. J. (2012). Trait-like vulnerability to total and partial sleep loss. Sleep, 35, 1163-1172. https://doi.org/ 10.5665/sleep. 2010

Smith, C. S., Reilly, C., \& Midkiff, K. (1989). Evaluation of three circadian rhythm questionnaires with suggestions for an improved measure of morningness. Journal of Applied Psychology, 74, 728. https://doi.org/ 10.1037/0021-9010.74.5.728

Van Dongen, H. (2004). Comparison of mathematical model predictions to experimental data of fatigue and performance. Aviation, Space and Environmental Medicine, 75, A15-A36.

Van Dongen, H. P. A., Baynard, M. D., Maislin, G., \& Dinges, D. F. (2004). Systematic interindividual differences in neurobehavioral impairment from sleep loss: Evidence of trait-like differential vulnerability. Sleep, 27, 423-433.

Van Dongen, H., \& Dinges, D. F. (2003). Investigating the interaction between the homeostatic and circadian processes of sleep-wake regulation for the prediction of waking neurobehavioural performance. Journal of Sleep Research, 12, 181-187. https://doi.org/10.1046/j. 1365-2869.2003.00357.x

Van Dongen, H. P. A., \& Dinges, D. F. (2005). Sleep, Circadian Rhythms, and Psychomotor Vigilance. Clinics in Sports Medicine, 24, 237-249. https://doi.org/10.1016/j.csm.2004.12.007

Wachowicz, B., Beldzik, E., Domagalik, A., Fafrowicz, M., Gawlowska, M., Janik, J., ... Marek, T. (2015). Different types of errors in saccadic task are sensitive to either time of day or chronic sleep restriction. PLoS One, 10, e0126502. https://doi.org/10.1371/journal.pone. 0126502

Williamson, A. M., \& Feyer, A.-M. (2000). Moderate sleep deprivation produces impairments in cognitive and motor performance equivalent to legally prescribed levels of alcohol intoxication. Occupational and Environmental Medicine, 57, 649-655. https://doi.org/10.1136/oem. 57.10.649

Zigmond, A. S., \& Snaith, R. P. (1983). The hospital anxiety and depression scale. Acta Psychiatrica Scand., 67, 361-370. https://doi.org/10. 1111/j.1600-0447.1983.tb09716.x

Zils, E., Sprenger, A., Heide, W., Born, J., \& Gais, S. (2005). Differential effects of sleep deprivation on saccadic eye movements. Sleep, 28 , 1109-1115. https://doi.org/10.1093/sleep/28.9.1109

How to cite this article: Pettersson K, Müller K, Tietäväinen A, Gould K, Hæggström E, . Saccadic eye movements estimate prolonged time awake. J Sleep Res. 2019;28:e12755. https://doi.org/10.1111/jsr.12755 